object, as has also that of $U$ Aurigae for another star, given in the list below. The variability of the other stars to which letters have been prematurely assigned in the V.J. S. has not been confirmed, so far as I know; and, in one case at least, the star will bear another letter than the one there given, even if the variability be confirmed, since there is a candidate which has the priority.

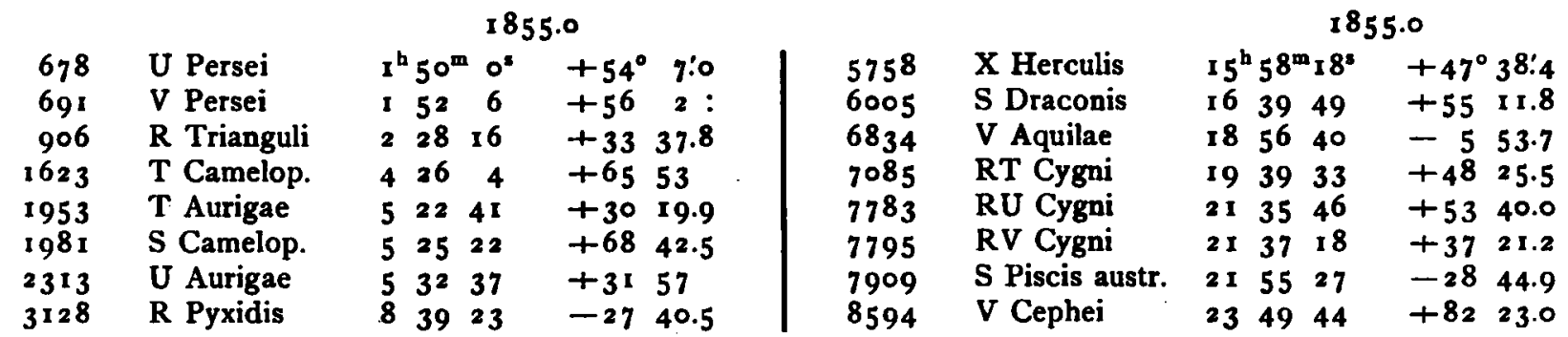

\title{
Observations de Comètes
}

faites a l'Equatorial coudé (om32) de l'Observatoire de Lyon par M. G. Le Cadet.

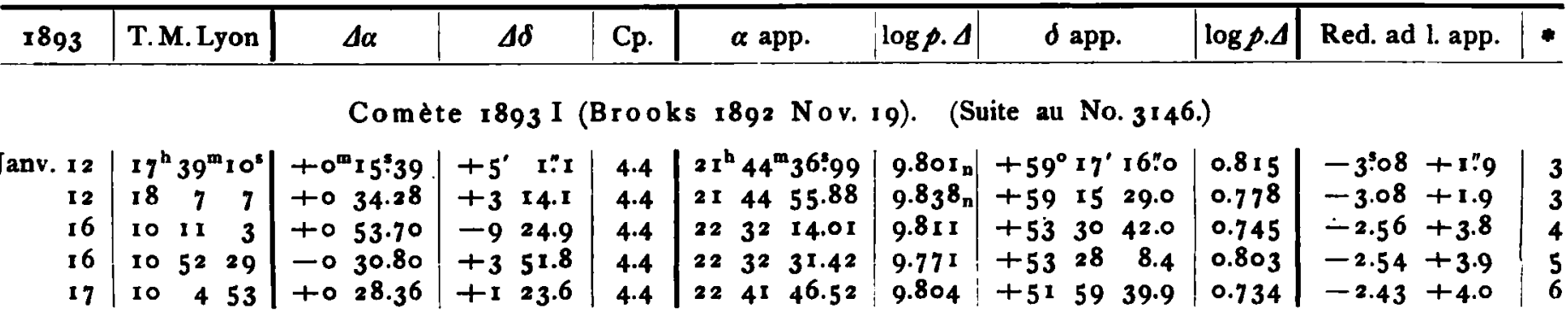

Comète 1892 III (Holmes). (Suite au No. 3139.$)$

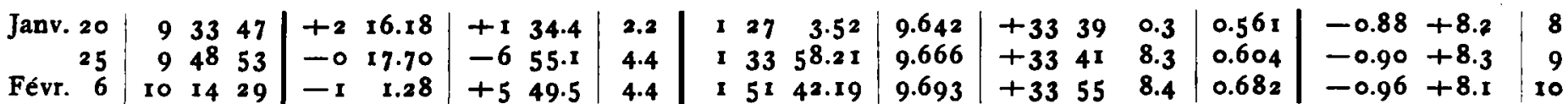

Remarques. Janv. 20. Observation faite dans une courte et brumeuse éclaircie. La comète se présente sous forme d'une brillante condensation nébuleuse de $9^{\circ}$ grandeur. - Févr. 6 . Comète redevenue très-faible, presque sans condensation; nébulosité un peu allongée vers le $\mathrm{NE}$; dans ce sens son étendue est de $5^{\prime}$ environ: elle s'est trèssensiblement étalée depuis le 20 Janvier.

Positions moyennes des étoiles de comparaison pour r893.0.

\begin{tabular}{|c|c|c|c|c|c|c|c|}
\hline$*$ & $\alpha$ & $\delta$ & Autorite & $\bullet$ & $\alpha$ & $\delta$ & Autorité \\
\hline $\begin{array}{l}3 \\
4 \\
5 \\
6\end{array}$ & $\begin{array}{rrr}2 \mathrm{I}^{\mathrm{h}} & 44^{\mathrm{m}} & 24^{3} \cdot 68 \\
22 & 3 \mathrm{I} & 22.87 \\
22 & 33 & 4.76 \\
22 & 4 \mathrm{I} & 20.59\end{array}$ & $\begin{array}{rr}+59^{\circ} 12^{\prime} & 13.0 \\
+5340 & 3.1 \\
+5324 & 12.7 \\
+515812.3\end{array}$ & $\begin{array}{l}\text { Hels. AG. Z. } 399 \\
\text { AG. Camb. } 7791 \\
\text { AG. Camb. } 781 \text { I } \\
\text { AG. Camb. } 7903\end{array}$ & $\begin{array}{r}8 \\
9 \\
10\end{array}$ & 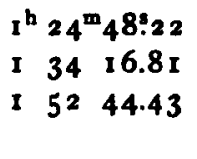 & $\begin{array}{l}+33^{\circ} 37^{\prime} 17^{\prime \prime} 7 \\
+334755.1 \\
+334910.8\end{array}$ & $\begin{array}{l}\text { Leid. AG. Z. } 242 \\
\text { Leid. AG. Z. } 397,398 \\
\text { Leid. AG. Z. } 393,396\end{array}$ \\
\hline
\end{tabular}

St. Genis Laval 1893 Févr. I I.

Georges Le Cadet.

Notiz betr. BD. -0.2309 .

La stellina di 9:5 BD. - -0.2309 riferita a BB. VI -0.2307 è (1855.0):

$$
10^{\mathrm{h}} 6^{\mathrm{m}} 23^{\mathrm{s}} 57 \quad-0^{\circ} 28^{\prime} 54^{\mathrm{t}} 9 \text {. }
$$

E. Millosevich. 